\title{
PWS Preparations
}

\section{Rhoda L. Ross-Williams*}

Department of Social Impact Management, Walden University, Florida, United States

*Corresponding author: Rhoda L. Ross-Williams, Department of Social Impact Management, Walden University, Florida, United States, Tel: + 2292514089; E-mail: rosswilliamsrhoda@gmail.com

Received date: July 25, 2018; Accepted date: September 10, 2018; Published date: September 17, 2018

Citation: Ross-Williams RL (2018) PWS Preparations. J Rare Disord Diagn Ther. Vol.4 No.4: 20.

Copyright: (C) 2018 Ross-Williams RL. This is an open-access article distributed under the terms of the Creative Commons Attribution License, which permits unrestricted use, distribution, and reproduction in any medium, provided the original author and source are credited.

\section{Abstract}

Prader-Willi Syndrome is a complex chromosomal birth defect that causes neurological disorders, health issues, and insatiable appetites. Lifelong care for PWS patients is complex because their physical health issues cause psychological behavior issues that require unique strategies. PWS patients have unique needs in schools, community programs, and adult care programs and if they do not receive proper care it is life threatening. Therefore, parents must seek professional expert support to develop lifelong preparations with securities plans to foster the best interest of their PWS child. The Children's Institute (TCI) Center for PWS in Pittsburgh, Pennsylvania and PWSA USA are resources for PWS expert support in America with over 20 years of experience. The challenges PWS families face with adult programs is a crisis that requires national support from the Department of Health and Human Services.

\section{Preparations with Securities}

Prader-Willi Syndrome (PWS) is a rare disease resulting from a deletion of the paternal alleles in the 15 q11-q13 region causing a neurodevelopmental disorder [1]. This condition does cause hyperphagia, the inability to stop eating because PWS hypothalamic disorders create an insatiable appetite along with psychological behavioral disorders [1]. PWS effect on the hypothalamus causes neurological psychological behavior disorders [1]. The behavioral issues of PWS do not show the first few years of their lives between the ages of 0-3 [2]. However, as the patients mature many physical and psychological health issues develop resulting from their multiple endocrine system issues [2]. Because PWS patients can easily choke to death or eat until their stomach ruptures the parents of PWS patients must begin preparations to secure a safe and wholesome life for their child as they transition to school, community-based programs, and assistant living group (ALG) homes [3]. PWS patients need PWS specific community programs and ALG homes because the dangers foods create yet there is a shortage of providers [4].

\section{Life Long Care}

Since PWS has a prevalence rate of 1:10,000-1:30,000 many schools, community programs for the disabled, and adult assisted living facilities lack proper training to foster the best interest of the PWS patients [1,3]. Therefore, schools and community-based programs need the expertise of certified professionals that have hands on experience working with PWS patients. PWS patients' behaviors have four phases in life ranging from barely eating to over eating [4]. Most PWS infants can barely suck a bottle and many have feeding tubes the first year of their life [4]. This is why parents are not strict about food consumption once the toddlers show interests in eating food. However, it is necessary for parent to receive proper education regarding food and nutrition with the PWS child to prevent the rapid on set of morbid obesity that starts between the ages of three to five years old [4]. The children are experiencing some major health and life changes at the pre-kindergarten and kindergarten ages as they begin attending school. Parents excited as the PWS child is beginning school until the reality of the new challenges appear in the school setting. This is why school and parent must seek expert support service to prevent issues that do not foster the best interest of the PWS child. Parents can become overwhelmed as they attempt to learn the complex world of special education law accompanied with their daily PWS caregiver challenges. The Individuals with Disabilities Education Act (IDEA) is a law that provides disabled students proper services and accommodations that school systems must follow [5]. Students have an individualized educational plan (I.E.P.) that is the I.E.P. team drafts and it should foster the best interest of the child according to their exceptionalities [5]. In the case of PWS student food exposure and securities to foster the best interest of the child should be in their I.E.P. Children with PWS have unique needs that can conflict with the format of a special education classroom especially least restrictive environment (LRE) [5]. Food is a health and safety hazard for PWS patients and does prevent them from participating in activities with food Ogata et al. Psychological behavioral issues are less likely to occur with PWS patients regarding food when food is out of sight and out of mind [2]. PWS is a neuro developmental disorder because the hypothalamus is compromised affecting the entire endocrine system of the patient they are always hungry and obsessively compulsive [1]. 
PWS patients' psychological behavioral issues are medical rather than mental health because hormonal and neurological issues cause chemical imbalance affecting the brain [6]. The behaviors are unique requiring special behavior management techniques. Expert consultative services for school systems and adult programs are necessary to serve PWS patients properly. Dr. Amy L. McTighe of The Children's Institute (TCI) Center for PWS in Pittsburgh, Pennsylvania is the Prader-Willi Syndrome Program Manager; she is an expert on PWS care in schools, community based programs, and ALG homes providing consultation services for schools and providers [3]. TCI PWS program record stands at improving the lives of nearly 1,500 children and adults with Prader-Willi syndrome with their experts' services [3]. School systems special education departments and adult programs will learn behavior management, teaching techniques, and many more skills to service PWS patients properly [3]. These services are a good resource for schools because IDEA requires school system to cover the needs of each student according to their exceptionality. Expert services are necessary more as PWS students become older causing difficulties in school settings because of hormonal imbalances with maturity $[2,3]$. Once parent get the diagnoses of PWS they need to start preparations with securities to meet the lifelong needs of the patients. Parents should exercise their rights under IDEA and American with Disabilities Act (ADA) requiring school systems and adult program providers to start utilizing the Care Coordinator Program of $\mathrm{TCl}$ to minimize the stress level for parents and issues for patients. PWS Care Coordination program of $\mathrm{TCl}$ consists of a physician, registered nurse, and other experts are available when necessary to meet the critical needs of the patient and family [3]. The consultation team members are physical therapist, occupational therapist, speech and language therapist, registered dietician, and a special education teacher that specialize in PWS medical, educational, and community needs [3]. The needs of PWS patients change as they transition into adulthood and a new set of challenges come with this milestone and $\mathrm{TCl}$ consultation services is a resource that adult providers for community programs and ASL need to use to foster the best interest of PWS patients.

\section{Adult Needs}

The transition into adulthood is the time parents see the most challenges with a PWS child becoming an adult [3]. Prader-Willi Syndrome Association USA (PWSA USA) is a national organization that keeps data on research findings and medical needs for PWS patients [4]. PWSA USA data shows an increasing life expectancy of patients increasing the need for adult PWS day programs and ALG homes [4]. Many families in the PWS community are encountering a shortage of PWS specific adult community based daytime care programs and adult ALG homes this is a problem because there are many lifethreatening dangers from food exposure [4]. PWS adults' probability of death from food exposure is higher because they are more independent. This is why preparations with securities is a lifelong care plan each PWS parent need to avoid having legal, medical, and financial issues while caring for their adult
PWS child. The department of health and human services provides funding for each states medical programs [7]. One valuable service for chronically disabled children and adults including intellectual disabilities is state Medicaid waiver that provides funds for in home care, adult community programs, and ALG homes [7]. Many parents of PWS patients are not aware that they should obtain a Medicaid waiver from their state to receive funding to pay adult care providers. Therefore, they have a new PWS challenge because they must have waiver funding to pay for these adult daytime care services and ALG homes providers. If parents do not have, the Medicaid waiver when PWS patients complete high school the waiting list for a waiver can be over five years in some states [7]. Therefore, parents should take advantage of the fact that IDEA allows students to attend public school until they become 21 years old. It is wise for parents to apply for Medicaid waiver services prior to their child's first year of high school so they can have waiver approval when they graduate. Even with funding, the greatest challenge is finding a PWS specific adult day care program and ALG home provider. This is a problem because it is dangerous for an adult PWS patient to participate in adult day care programs and ALG homes that are not PWS specific risking food exposure deaths [3]. Food exposure is the greatest threat because intellectually disabled adults have access to food in adult programs causing PWS patients to consume foods beyond their daily caloric count [2]. The patients can become morbidly obese if the consume too many calories per day. Morbid obesity creates life threatening health issues for the PWS patient such as pulmonary hypertension, fatty liver disease, type two diabetes, hypertension, heart problems, and many more health problems [4]. Adult PWS needs are more complex than caring for a child with PWS and many parents discover this as they are becoming overwhelmed seeking PWS specific services. Parents need to utilize the help of expert organizations and facilities to help them with their preparations with securities for the lifelong challenges of PWS. PWSA USA has a family support team, medical crisis team, advocates, advisors, and other services to assist PWS caregivers [4]. As parents prepare for the lifelong needs of their PWS child they should develop, a collective voice demanding more PWS specific adult daycare programs and assisted living facilities. Parents need to connect with PWSA USA and their state PWS organization for strategic planning to end this shortage of PWS specific adult programs in their state. In addition if your PWS adult is in a none specific PWS program that program should use TCI PWS consultation services.

\section{Contact Information for Expert Consult and Support Services}

Dr. Amy L. McTighe of The Children's Institute (TCI) Center for PWS in Pittsburgh, Pennsylvania is the Prader-Willi Syndrome Program Manager. She can be contacted via email at amt@the-institute.org, phone (412) 420-2436, or fax (412) 420-2166. The website for the programs is www.amazingkids.org/pws. Also, PWSA USA is a resource parents and caregivers need to utilize as well. The phone number for the organization is (800) 926-4797. Their website 
address is www.pwsausa.org. Parent and caregivers will find medical emergency information they will need when taking their PWS child for emergency medical care and much more valuable information on the website. These two contacts are a great points of reference when seeking expert services for your PWS child both have over 20 years of experience.

\section{Conclusion}

A diagnosis of PWS is beyond medical care it is a holistic plan inclusive of all the needs a PWS patient will have in their life. Parents and caregivers of PWS patients have a lifelong commitment and proper preparation with securities fosters the best interest of their child. The stages of caregiving do not become easier however using the services of experts that specialize in meeting the needs of PWS patients reduces the difficulties families will face with PWS children. Therefore, parents should apply for the Medicaid waiver in their state that gets funding through the U.S. Department of Health and Human Services. Despite the funding for providers, the greatest challenge the PWS community faces is a shortage of adult day care programs and assisted living programs specifically for PWS patients. The PWS community needs a central point of contact to start creating more PWS specific adult day programs and ALG homes. HHS would be instrumental in offering special funding opportunities for PWS specific adult providers. In conclusion, this growing problem requires all PWS parents and caregiver to request the department of health and human services begin a national program specifically for PWS adult day care and assisted living programs because it is the necessary preparations with securities these patients need to end the shortage of PWS specific adult day programs and ALG homes providers.

\section{About the Author}

Rhoda L. Ross-Williams is a parent of a child with PraderWilli Syndrome. She is an ADA and IDEA advocate, author, and
HR consultant. Rhoda's advocacy for her daughter's rare disease PWS is featured in the New York Times Magazine January 25th, 2015 publication in an article titled Food is a Death Sentence to These Kids by Kim Tingley. Rhoda is the author of Positive Winning Soul Defeating Prader-Willi Syndrome and a coauthor to Leave Your Baggage Behind: Letting go of the past and healing for the future. Rhoda's higher educational background is a Bachelor's degree of Science in Human Resources Management from Park University, M.B.A. specializing in Human Resources Management from Walden University, all but dissertation post graduate specializing in Social Impact Management from Walden University, and a research certification from the National Institute of Health. Rhoda L. Ross-Williams can be contacted via email at rosswilliamsrhoda@gmail.com.

\section{References}

1. Griggs JL, Sinnayah P, Mathai M (2015) Prader-Willi syndrome: From genetics to behaviors special focus on appetite treatment. Neurosci Biobehav Rev 59: 155-172.

2. Ogata H, Ihara H, Gito M, Sayama M, Murakami N (2018) Aberrant, autistic, and food-related behaviors in adults with Prader-Willi syndrome. The comparison between young adults and adults. Res Dev Disabil 73: 126-134.

3. The Children's Institute: Prader -Willi Syndrome Treatment and Management. http://www.amazingkids.org/pws

4. Prader-Willi Syndrome Association USA. https:// www.pwsausa.org/

5. Brown J, Ernst J, Clark A, DeLuca VW, Kelly D, et al. (2018) Working with special populations. Technology \& Engineering Teacher 77: 10-13.

6. Benarroch F, Hirsch H, Genstil L, Landau Y, Gross-Tsur V, et al. (2007) Prader-Willi Syndrome: Medical Prevention and Behavioral Challenges. Child Adolesc Psychiatr Clin N Am 16: 695-708.

7. Department of Health and Human Service 2018. 